\title{
How does quality of care relate to a rights-based approach to family planning programs?
}

Jan Kumar

Follow this and additional works at: https://knowledgecommons.popcouncil.org/departments_sbsr-rh

Part of the Demography, Population, and Ecology Commons, Family, Life Course, and Society Commons, International Public Health Commons, Maternal and Child Health Commons, and the Women's Health Commons How does access to this work benefit you? Let us know!

\section{Recommended Citation}

Kumar, Jan. 2015. "How does quality of care relate to a rights-based approach to family planning programs?" Working Paper 1 of the Measuring and Monitoring Quality of Services and Quality of Care Project. New York: Population Council. 


\section{HOW DOES QUALITY OF CARE RELATE TO A RIGHTS-BASED APPROACH TO FAMILY PLANNING PROGRAMS?}

Jan Kumar

THE David $\varepsilon$

Lucile Packard Foundation
(2OPULATION COUNCIL

Ideas. Evidence. Impact. 


\section{Popuration \\ Ideas. Evidence. Impact.}

The Population Council confronts critical health and development issues-from stopping the spread of HIV to improving reproductive health and ensuring that young people lead full and productive lives. Through biomedical, social science, and public health research in 50 countries, we work with our partners to deliver solutions that lead to more effective policies, programs, and technologies that improve lives around the world. Established in 1952 and headquartered in New York, the Council is a non-governmental, non-profit organization governed by an international board of trustees.

Population Council

One Dag Hammarskjold Plaza

New York, New York 10017

\section{popcouncil.org}

Suggested citation: Kumar, Jan. 2015. "How Does Quality of Care Relate to a Rights-based Approach to Family Planning Programs?" New York: Population Council. 


\section{Table of Contents}

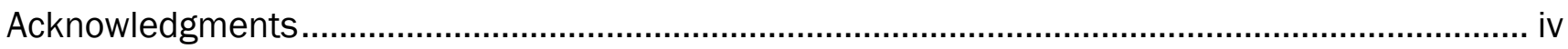

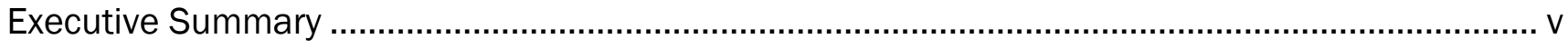

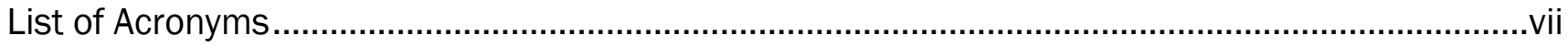

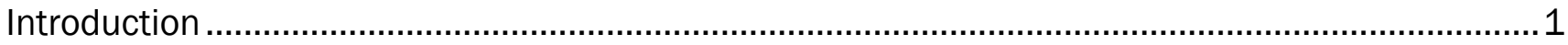

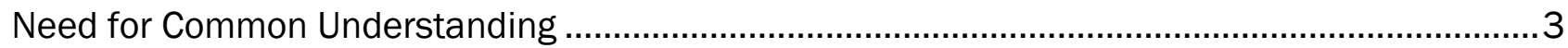

Why Focus on Quality of Care in Family Planning? ...........................................................

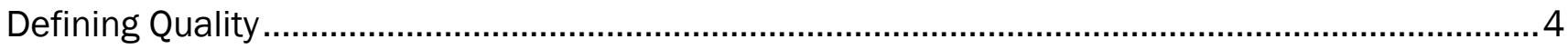

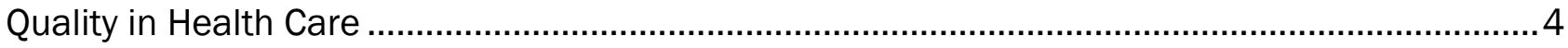

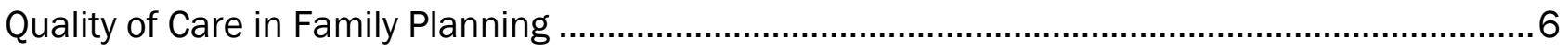

Quality in Health System, Program and Service Delivery Models .............................................

How Do Quality and Service Delivery Models Relate to a Rights-Based Approach? .................... 11

Human Rights that Pertain to Family Planning Programs ................................................ 11

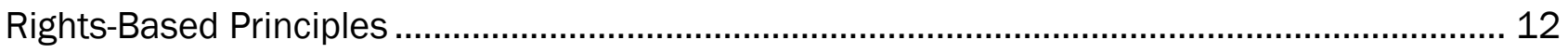

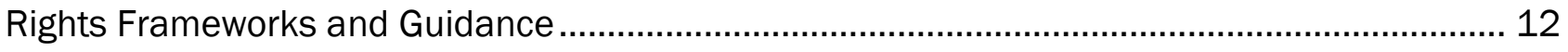

What Additional or Different Inputs Does a Rights-Based Approach Require? ........................ 15

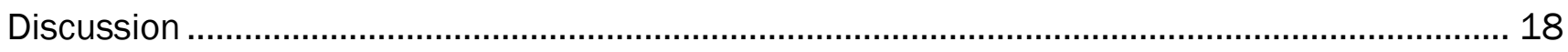

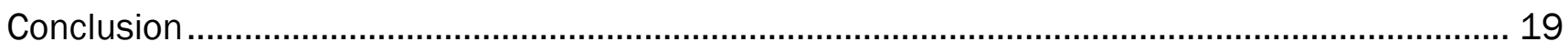

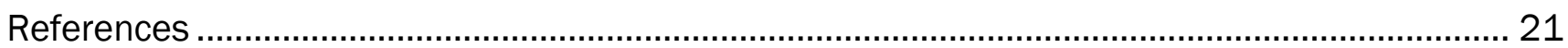




\section{Acknowledgments}

This review has been prepared by Jan Kumar under the Measuring and Monitoring Quality of Services and Quality of Care project funded by a grant to the Population Council from the David and Lucile Packard Foundation. We gratefully acknowledge the Packard Foundation's support and encouragement for continuing research on the current state of quality of care.

Ms. Kumar would also like to acknowledge the contributions of Anrudh K. Jain, John W. Townsend, lan Askew, and Saumya RamaRao of the Council for their reviews of earlier versions of this report. 


\section{Executive Summary}

Quality of care has long been a pillar of health care in general and family planning programs in particular. However, the theme has been getting less attention in recent years and its meaning has gotten blurred, confusing the discourse and what it is donors and governments should invest in and monitor. The rationale for increasing and sustaining a focus on quality of care in Family Planning (FP) programs is twofold. It is a desired end in itself, both practically and ethically, as well as a means to other desired outcomes, such as greater continuation rates among satisfied users and more efficient supply systems. But different organizations define the term differently. The concept of quality has gotten conflated with the concept of rights-based. While there is overlap, the concepts are not synonymous. A lack of agreement on definitions and distinguishing characteristics of these two terms leads to insufficient attention to some important program elements. Both concepts are important and call for greater clarity to guide program design, quality assurance and improvement, and appropriate indicators for consistent monitoring and evaluation.

This paper compares definitions of quality and contrasts them with the essentials of a rights-based approach. It aims to create common understanding of what these terms mean, where they overlap and how they differ. The comparative review revealed that quality of care is essentially a supply-side construct that relates to the conditions and actions programs should ensure for their clients during service delivery. It is rooted in evidence-based medical science and focuses on the safety and effectiveness of services. Its orientation is primarily around the health system and service provider competencies and behaviors towards those they serve.

In contrast, a rights-based approach centers on the dignity, needs, and autonomy of individual clients and potential clients. It is about empowering and engaging people to exercise self-determination for their health and fertility, and eliminating policy and program barriers and practices, including all forms of discrimination, which would block anyone from enjoying their rights. While it includes quality of care, a rights-based approach is more an ethical model than a medical one. It is a broader programmatic construct than quality of care, reflecting all components of healthcare systems and programs, including the policy and cultural context in which they operate and both supply and demand. And unlike quality of care, a rights-based approach applies both to those served and those not served. It is characterized by participation, individual agency, and equity - with special attention to marginalized and vulnerable groups-and it stresses program accountability.

While a rights-based approach covers quality of care, the inverse is not true. Examples of where the narrow focus on quality fails to address the larger issues of human rights in healthcare include the following:

- With a narrow quality focus the voice and participation of clients and potential clients are often absent in both the planning of new services and the evaluation of existing efforts;

- When the focus is on the medical safety of clients served with little or no attention to the profile of who is and is not being served, the issue of equity is often overlooked. Focusing on quality for clients who avail themselves of services does not protect the rights of those who do not have access to services, for whatever reason;

- Quality of services does not address the policy environment in which those services are provided, which could limit method choice and/or create provider bias that compromises clients' full, free and informed choice.

- Access to quality family planning services does not in itself redress the problems of gender inequality and lead to women's empowerment; and

- The themes of governance and accountability are poorly understood and often addressed haphazardly at the health systems level. Both are rarely found in the analysis of quality of care, but are necessary for sustainable solutions to shortfalls in quality and for programs that seek to protect and fulfill the rights of all clients and potential clients. 
In its conclusion, this paper argues in favor of adopting the broader construct of rights-based programming as a foundation for family planning programs. Since this approach protects medical safety and effectiveness of services in addition to other human rights that pertain to healthcare, it offers a more comprehensive and appropriate foundation for programming. Programs should maintain a focus on service quality within the broader rights approach rather than limiting their focus to assuring and improving quality. Moreover, there is a strong ethical and legal rationale for taking an explicit and comprehensive, rights-based approach. Not only is it the right thing to do, but also governments have made legally binding commitments to respect, protect and fulfill human rights for their citizens. Beyond that, there is evidence that a rights-based approach enhances public health outcomes, and there is reason to believe that if applied comprehensively it could be a low-cost, high-impact game changer. We would have reason to expect greater community trust in the healthcare system, increased client satisfaction and use of services, and improved program sustainability.

An important next step is to reach agreement on a definition of quality of care in family planning that distinguishes it from a rights-based approach. With some modification, the widely accepted Bruce quality framework, which has guided international family planning for twenty-five years, could continue to serve us well going forward. We then need to position quality in the broader human rights context and adopt a full rights-based approach to programs, which orients planning, implementation, monitoring and evaluation in terms of clients, rather than systems, services or providers. This would make people's dignity and needs central to our efforts, and would prioritize engaging clients' voices and participation in all phases of programming.

To protect and fulfill the rights of both clients and potential clients, programs should institute safeguards to ensure that no one is pressured or induced into accepting a service they don't want, everyone has access to information, no one is denied care, and that services provided are of the best possible quality. Policy review is called for to identify and reform policies that could potentially compromise human rights, including eligibility criteria, numerical performance targets or indicators, incentives payments, and method-specific promotion. There is need for concerted effort and targeted investment to focus on reaching those who are most vulnerable and marginalized with information and services. Donors and governments should support expanded method choice and effective client counseling that protects clients' free and informed decision making. Rights literacy training for providers, supervisors and community members, and community engagement efforts should be made integral program elements. Respecting the dignity and autonomy of individual clients should be rewarded. Investments in strengthening accountability and redress mechanisms are needed. And the systematic application and evaluation of a rights-based approach, plus documentation and dissemination of results, should be prioritized on the global research agenda.

If donors would embrace, fund and hold governments accountable to the fullness of a rights-based approach to family planning with an explicit focus on assuring quality of care; and if governments and NGOs would embed rights principles in how they plan, implement and monitor their family planning programs, assuring access without discrimination, medical safety and full, free, informed choice for all, they would transform the path leading toward their ambitious FP2020 goals and eventually universal coverage of health services as called for by the Sustainable Development Goals for 2030. 


\section{List of Acronyms}

\begin{tabular}{|c|c|}
\hline AAAQ & Availability, Accessibility, Acceptability, Quality \\
\hline CIOMS & Council for International Organizations of Medical Sciences \\
\hline DHS & Demographic and Health Survey \\
\hline FP & Family Planning \\
\hline HIV/AIDS & Human Immunodeficiency Virus/Acquired Immune Deficiency Syndrome \\
\hline ICPD & International Conference on Population and Development \\
\hline IEC & Information, Education and Communication \\
\hline IIPS & International Institute for Population Sciences \\
\hline IPPF & International Planned Parenthood Federation \\
\hline IUD & Intrauterine Device \\
\hline MAQ & Maximizing Access and Quality \\
\hline MIS & Management Information System \\
\hline MLE & Measurement, Learning \& Evaluation \\
\hline MSI & Marie Stopes International \\
\hline NGO & Non-Governmental Organization \\
\hline QIQ & Quick Investigation of Quality \\
\hline PANEL & Participation, Accountability, Non-discrimination and equality, Empowerment and Links \\
\hline RBA & Rights-Based Approach \\
\hline $\mathrm{RH}$ & Reproductive Health \\
\hline RMNCAH & Reproductive, Maternal, Newborn, Child and Adolescent Health \\
\hline SARA & Service Availability and Readiness Assessment \\
\hline SPA & Service Provision Assessment \\
\hline SRH & Sexual and Reproductive Health \\
\hline UN & United Nations \\
\hline UNFPA & United Nations Population Fund \\
\hline URC & University Research Corporation \\
\hline URHI & Urban Reproductive Health Initiative \\
\hline USAID & United States Agency for International Development \\
\hline VRBFP & Voluntary, Rights-Based Family Planning \\
\hline WHO & World Health OrganizationInsert word \\
\hline
\end{tabular}




\section{Introduction}

Quality of care has been a focus of health care for nearly a century (Lee and Jones 19331, Donabedian $1966^{2}$ ) and of family planning (FP) programs specifically since the early 1990s (Bruce 19903, Huezo and Diaz 19934). After the initial focus on establishing FP services and generating demand in the early days of international FP programs, assuring the quality of those services became a legitimate concern for clients, advocates, donors, and governments. Donors and technical assistance organizations devoted increasing resources to strengthening the quality of clinical care and client counseling starting in the 1980s, with efforts peaking in the following two decades. This period produced a proliferation of quality assurance, quality improvement, and performance improvement tools and research on the impact of quality of care on client behaviors and health outcomes. USAID funded three global Quality Assurance Projects (led by University Research Corporation, URC) from 1990 to 2008, to raise awareness of the importance of quality standards and develop the capacity for quality improvement as a vital component of health system strengthening 5 . Meanwhile, the Ford Foundation funded a series of papers, Quality/Calidad/Qualité, by the Population Council featuring programs that demonstrated innovative approaches to high quality care in sexual and reproductive health (SRH). The Huezo-Diaz model of quality of FP services was based on a list of clients' rights, and Population Council's Quality series was rooted in recognition of "the fundamental right to respectful treatment, information, choice, and follow-up from reproductive health-care providers ${ }^{6}$."

Human rights in health can be traced to 1946 when the World Health Organization (WHO) Constitution first articulated the Right to Health, which has since been embellished and reaffirmed in international covenants, treaties, and comments conferring the weight of international law. In 2000, the United Nations (UN) Committee on Economic, Social and Cultural Rights issued General Comment 14 on the Right to Health, which stipulates essential elements and principles of this right that are legally enforceable? ${ }^{7}$.

The right to the highest attainable standard of health entitles people to health care information, services, and commodities that are:

Available: Sufficient quantity of goods, services, and functioning health care facilities staffed by trained and reasonably compensated personnel and supplied with essential drugs. The Comment allows for variation in "the precise nature of facilities, goods and services...depending on numerous factors, including the State party's developmental level."

Accessible: Comprised of four overlapping dimensions:

1. Non-discriminatory: offering goods and services to all, especially the most vulnerable or marginalized groups, in law and in fact;

2. Physically accessible: within safe physical reach for all sections of the population, especially vulnerable or marginalized groups, including in rural areas. This also includes adequate access to buildings for persons with disabilities.

3. Economically accessible: affordable for all, including the socially disadvantaged, based upon the principle of equity, "which demands that poorer households should not be disproportionately burdened with health expenses as compared to richer households;" with

4. Information accessibility: the right and ability "to seek, receive and impart information and ideas concerning health issues" without impinging on the right to confidentiality.

Acceptable: Respectful of medical ethics and culturally appropriate, sensitive to gender and life cycle requirements, and respectful of confidentiality.

Of Good Quality: "Health facilities, goods and services must...be scientifically and medically appropriate and of good quality. This requires, inter alia, skilled medical personnel, scientifically approved and unexpired drugs and hospital equipment, safe and potable water, and adequate sanitation $7 . "$ 
The explicit stipulation of quality in this articulation of the Right to Health established medically appropriate and good quality health care as a human right that governments and other actors are legally obligated to respect, protect, and fulfill.

The intersection of human rights and FP specifically has been recognized since the 1960s, although early articulation of reproductive rights spoke of couples' rights, rather than individuals' rights. At the 1968 Conference on Human Rights in Tehran, participating States proclaimed couples' basic human right to decide freely and responsibly the number and spacing of their children, and to related information (UN 1968) $)^{8}$. The next year the UN General Assembly reaffirmed this right and added that couples also have the right to contraceptives ("the means necessary") (UN 1969) ${ }^{9}$. These rights were reiterated and embellished in the 1994 International Conference on Population and Development (ICPD) Programme of Action, which is noted for its global call for the empowerment of women and the promotion of gender equity and equality. It recognized the rights of individuals, as well as couples, "to enjoy the highest attainable standard of sexual and reproductive health" and "to make decisions concerning reproduction free of coercion, discrimination and violence ${ }^{10}$." These rights were reaffirmed at the Beijing Women's Conference in 1995, by the Convention on the Elimination of all forms of Discrimination Against Women (CEDAW 1998), and by numerous other declarations. This global commitment to ensuring universal access to contraceptive information and services, free choice, and RH has become the bedrock of FP programs internationally.

Despite this commitment, the history of FP is stained by human rights violations in a range of countries in the form of coercion, barriers to accessing information or services, limited choice of method or of family size, and poor quality. Some cases have been systemic and widespread, rooted in policy, as in China's one child policy that was in effect for 35 years (1980 to 2015) and the forced sterilization of poor, indigenous women in Peru in the late 1990s. Some have been the unintended consequences of management practices like performance targets, method-specific promotion meant to expand service access or options, or of resource constraints. Still others result from poor, unsanctioned practices by individual providers who lack adequate training or oversight, or indeed lack respect for individual human rights.

Clients' dignity and rights, particularly women's, have become more central to health initiatives and other development efforts in the last 20 years. In 1997 the UN declared human rights a cross-cutting issue and mandated its inclusion in all UN agency activities ${ }^{11}$. The entire UN system, including UNFPA, adopted a rightsbased approach to development cooperation and programming in 2003. Non-governmental organizations (NGOs) such as CARE, Oxfam, Save the Children, and Catholic Relief Services have done the same within their respective mandates. The human rights context for FP and RH established at ICPD in 1994 was emphasized again by the 2012 Family Planning Summit in London (FP2020). FP2020's ambitious goal of providing FP services to 120 million additional women and girls has heightened awareness of the need for ensuring FP programs respect, protect, and fulfill individuals' human rights. In 2014 both WHO and FP2020's Rights and Empowerment Working Group issued guidance on how to ensure human rights in the provision of contraceptive information and services ${ }^{12,13}$.

Service delivery and program initiatives and models have incorporated elements of both quality of care and rights-based approaches over time, including USAID's Maximizing Access and Quality (MAQ) Initiative, EngenderHealth's comprehensive SEED programming model underpinned by the Fundamentals of Care, and Marie Stopes International's service delivery model. All efforts to expand service access, strengthen clinical quality, increase method options, ensure informed choice, and promote gender equality and youthfriendly services support human rights, even if expressed in FP terms rather than rights-related language. The Voluntary Rights-based FP Framework developed by Hardee et al. (2013) intentionally merges quality of care, holistic programming, and human rights frameworks into a single construct, and notes which reproductive rights specific FP program elements support in practice ${ }^{14}$. Policymakers are challenged by numerous, overlapping constructs that create confusion about terminology, and about how different concepts and frameworks relate to one another, and thus which one to adopt. Many erroneously think ensuring quality of care is synonymous with a rights-based approach, although quality is just one component of one of several human rights that pertain to FP care. Similarly, within USAID circles, some confuse compliance with the Tiahrt Amendment (a US government statute intended to ensure voluntary FP use in US-supported programs) with a rights-based approach, when in fact the two are not equivalent. 


\section{NEED FOR COMMON UNDERSTANDING}

There is a need for common understanding of each construct, of what inputs each entails and what value it contributes to FP, and indeed all service programs in the reproductive, maternal, newborn, child and adolescent health (RMNCAH) field (i.e. expected outputs), inluding its benefits to the people these programs are meant to serve. This would facilitate productive discourse and drive donors' and governments' critical decisions about program investment priorities, program design, resource deployment, monitoring and evaluation plans, and establish a basis for generating evidence about the efficacy and impact of different models and approaches. It would also serve to heighten awareness of individuals' entitlements (as rights holders) and of the roles and responsibilities of those required by international law to respect, protect, and fulfill those entitlements (duty bearers). This paper responds to this need by identifying, clarifying, comparing and contrasting key quality of care definitions and frameworks, broader service delivery models and rightsbased approaches in FP programs. It focuses on the models and frameworks of key international institutions and initiatives, but does not reflect an exhaustive review of the literature.

\section{WHY FOCUS ON QUALITY OF CARE IN FAMILY PLANNING?}

There are two compelling rationales for increasing and sustaining a focus on quality of care in FP programs. First, it is a desired end in itself and second, it is a means to other desired outcomes such as greater continuation rates among satisfied users or more efficient supply systems.

Quality information and services in healthcare programs, including FP programs, is an explicit element of the Right to Health, a legally binding obligation of all governments to their citizens ${ }^{7}$. According to the UN Office of the High Commissioner on Human Rights, all countries have ratified at least one international human rights treaty recognizing the right to health. Furthermore, States have committed themselves to protecting this right through international declarations, domestic legislation and policies, and at international conferences ${ }^{15}$. There is thus a legal and ethical imperative for programs to ensure the highest possible standard of quality in their FP programs. The International Covenant on Economic, Social and Cultural Rights recognizes that States have resource constraints and competing priorities that prevent them from addressing all deficiencies immediately. It therefore allows for "progressive realization" of the elements of the Right to Health.

At the same time, resource constraints are not a permissible reason for lack of quality improvement. States are required to show "that they are making every possible effort, within available resources, to better protect and promote all rights under the Covenant ${ }^{15}$."

Assuring and improving health care quality also has practical benefits. Several studies have found that high quality services contribute to increased FP service demand and use (including new users, continued users and referrals by satisfied users) ${ }^{16-22}$, with impact on other desired $\mathrm{RH}$ outcomes including reduced unmet FP need, rates of unintended pregnancy and abortion, morbidity, and mortality. Good quality FP is a proximate determinant of client satisfaction with services and trust in the health care system. There is also some evidence that quality of care in other health sectors can contribute to cost effectiveness by maximizing

efficiencies and results with existing resources ${ }^{23,24}$. It is reasonable to assume this extends to FP as well: By reducing complications, requests for early removal of IUDs and implants, and return visits for common side effects, better clinical quality and counseling can lead to cost savings. Thus quality is desirable as a means as well as an end. 


\section{Defining Quality}

Quality in health care generally, and FP specifically, is a multi-dimensional construct with no shortage of definitions and frameworks. Not only do various organizations and projects define it differently, so do different stakeholders. Policymakers' perspectives on quality likely vary from service providers', as they focus on different elements under their purviews, and clients may value different elements of quality than other stakeholders, and may also have lower expectations of quality. Health care quality has many components affected by actions at several levels of a health system (policy, management and leadership, service delivery, and community). It is manifested at multiple levels of analysis and impact (individual, service delivery point, community, district, country). Quality pertains to both clinical practice and communications and support for decision making. It is an attribute of supply and influences demand for services. WHO has issued international guidelines for medical eligibility, safe clinical practice, and counseling for each contraceptive method offered ${ }^{25}$ that establish the desired level of quality for FP programs globally. . This is the gold standard governments use to develop their national standards and guidelines, providing reference points for defining the gaps between the actual and desired levels of quality in their programs and formulating quality improvement strategies.

Several widely accepted definitions of quality of care follow.

\section{QUALITY IN HEALTH CARE}

In the 1960s Avedis Donabedian based his framework for evaluating the quality of medical care upon Lee and Jones's criteria for good medical care, defined more than 30 years earlier ${ }^{1}$. They asserted that quality healthcare:

- Is limited to the practice of rational medicine based on medical science;

- Emphasizes prevention;

- Requires intelligent cooperation between the lay public and practitioners of scientific medicine;

- Treats individuals as whole persons;

- Maintains close and continuing personal relations between physicians and patients;

- Is coordinated with social welfare work;

Coordinates all types of medical services, and

- Applies all necessary services of modern, scientific medicine to the needs of all the people.

This construct is anchored in the science of good medical care, and adds the concepts of good client and provider relations, continuity of care, and equitable access for all people. Donabedian built upon these criteria to identify three essential dimensions for evaluating health care quality: structure (the setting, staffing, and financing supporting the delivery of care), the process of service delivery (including all actions and interactions by and between patients and providers), and outcomes (resulting changes in health status, behavior, knowledge, and satisfaction of patients and populations) ${ }^{2}$.

General Comment 14 on Article 12 of the Right to Health, which came many years later (2000), articulates four essential elements necessary for individuals to enjoy "the highest attainable standard of health," namely availability, accessibility, acceptability, and good quality. The UN Committee on Economic, Social and Cultural Rights stipulated that quality requires "skilled medical personnel, scientifically approved and unexpired drugs and hospital equipment, safe and potable water, and adequate sanitation ${ }^{7}$." It further stated that governments are obligated to protect and fulfill this right without any discrimination, with progressive steps towards full realization of this obligation, which is enforceable by international law and by national laws, both civil and criminal, where applicable. The Comment explicitly implicates professional associations and other NGOs in this responsibility. 
WHO defines quality care in terms of health systems and the quality of outcomes they produce. It calls for health systems to improve quality in six dimensions, to make health care ${ }^{26}$ :

- Effective: adhering to an evidence base and results in improved outcomes, based on need;

- Efficient: maximizing resource use and avoiding waste;

- Accessible: geographically reasonable, provided in a setting where skills and resources are appropriate to medical needs;

- Acceptable and patient-centered: accounting for individuals' preferences and aspirations and the cultures of their communities;

- Equitable: quality does not vary because of personal characteristics such as gender, race, ethnicity, geographical location or socioeconomic status; and

- Safe: minimizing risks and harms to service users.

Interestingly, this definition incorporates two other components of the right to health (Comment 14, Article 12), accessibility and acceptability, as elements of quality, whereas the right to health represents these components as separate from and of comparable value to quality. Making acceptability part of the definition of quality incorporates the client's perspective into the construct. Stipulating that quality health care is equitable, that it does not vary due to differences in personal characteristics, echoes Jones and Lee's criterion that evidence-based medicine should be applied to the needs of all people. This establishes a strong foundation for social justice in health care.

Under its Quality Assurance Project, URC identified dimensions of quality as the basis for quality improvement and assurance in health care ${ }^{27}$, several of which align with WHO's definition (effectiveness, efficiency, accessibility, safety) and some of which are closer to Lee, Jones, and Donabedian's frameworks (good interpersonal relations, service continuity, good infrastructure, comfort).

Community-defined quality and community-driven quality in health care delivery are e additional constructs with currency in some circles. They do not start with a definition of quality, rather a context-specific definition is an outcome of a collaborative process that develops partnerships between community members and health care professionals. The idea is to meaningfully engage consumer advocates to define quality of care from a consumer perspective, and to involve communities in active partnership with health workers in creating a vision for quality services and improving and monitoring service delivery operations, safety, interactions with health personnel, and efficiency. The definition and priority issues therefore vary from community to community.

The framework in Figure 1, developed under the MAQ Initiative based on work by Save the Children, has been adopted by the WHO-supported UPTAKE Project28.

FIGURE 1 COMIMUNITY-DRIVEN QUALITY FRAMEWORK

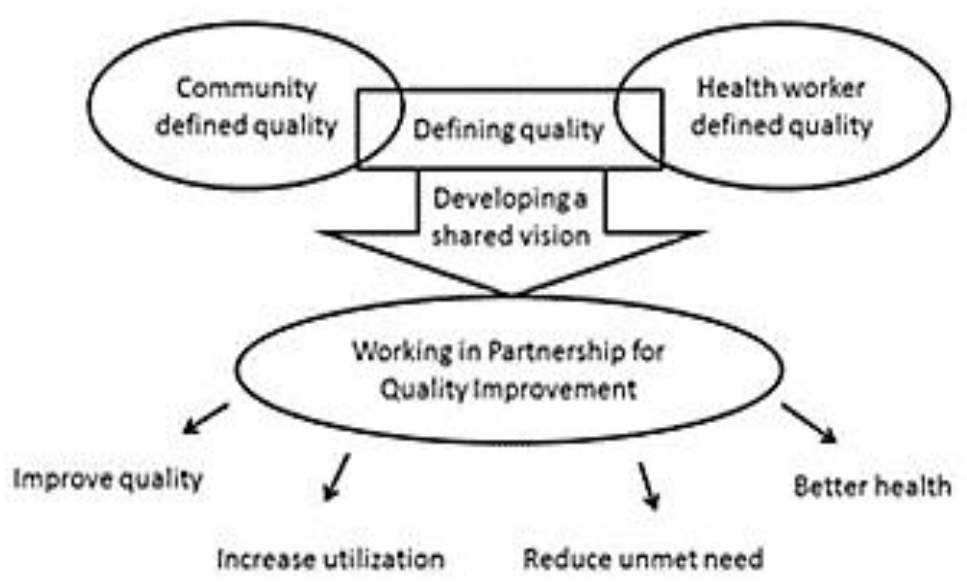

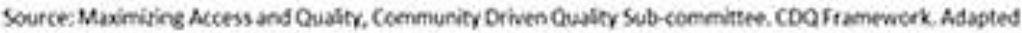

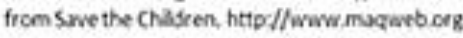




\section{QUALITY OF CARE IN FAMILY PLANNING}

In 1990 Judith Bruce published a foundational framework for quality of care specifically for FP programs, identifying six essential elements ${ }^{3}$ :

- Choice of methods, both number of options and range of method attributes;

- Information provided to clients to enable their informed choices and correct use of their chosen methods;

- Technical competence of service providers;

- Interpersonal relations between clients and providers, as influenced by the program mission, values, resources and management;

- Follow up through formal and informal mechanisms to encourage continuity of care; and

- Appropriate constellation of services to ensure FP services are convenient and acceptable to clients, and responsive to their needs.

Several elements of this framework are consistent with definitions of quality for health care writ large. It includes technical competence as a proxy for safety and adds the concept of informed choice and method options specific to elective FP services.

In developing their FP-specific quality of care framework, Huezo and Diaz (1993) ${ }^{4}$ took a different approach, framing quality in terms of clients' rights and what service providers, as duty bearers, need to fulfill their responsibility to protect and fulfill clients' rights. The framework recognizes quality of care as a client's right in and of itself, and lists the right to 10 service elements identified by IPPF as necessary to achieve quality of care in FP programs (Table 1 ).

The Bruce and Huezo-Diaz frameworks overlap, but the specifics of the non-medical aspects of quality to which individuals are entitled (privacy, confidentiality, dignity, comfort, opinion) are more explicit in the latter.

TABLE 1

To clarify the concept of quality of reproductive health care, which obviously includes FP, the EC/UNFPA Initiative for Reproductive Health in Asia identified nine key determinants of the quality of care, from a health system perspective ${ }^{29}$ :

- Providers' technical competence (including effectiveness of clinical action)

- Providers' interpersonal skills

- Availability of basic supplies, equipment, and logistics

- Accessibility of services (geographic, financial)

\begin{tabular}{ll}
\hline Clients' rights & Providers' needs \\
\hline Information & Training \\
Access & Information \\
Choice & Infrastructure \\
Safety & Supplies \\
Privacy & Guidance \\
Confidentiality & Backup \\
Dignity & Respect \\
Comfort & Encouragement \\
Continuity & Feedback \\
Opinion & Self-expression \\
\hline
\end{tabular}

- Quality of physical facilities and infrastructure

- Links to other health services, integration of services

- Functional and effective referral systems

- Continuity of care

- Informed decision-making.

It also notes specific support functions within health systems that have direct bearing on quality of care:

- Staffing

- Training

- Supervision

- Information, education, and communication (IEC)

- Record keeping and management information systems (MIS). 
While these definitions vary, they all derive from a medical model that prescribes the application of evidencebased, medical science to ensure the safety and effectiveness of health care services. They take a fundamentally supply side perspective that focuses on service delivery, itemizing the conditions, competencies, and transactions that the health system and individual health care workers are expected to provide clients. Most definitions include elements of interpersonal relations. The Bruce and Huezo-Diaz frameworks go farthest in defining quality in terms of client perspectives and experiences.

Definitions are theoretical. What matters is how the concept of quality is framed within health system, program, and service delivery models, and how it is applied and monitored in actual practice.

\section{QUALITY IN HEALTH SYSTEM, PROGRAM AND SERVICE DELIVERY MODELS}

Many organizations, projects, and initiatives have developed their own service delivery and program frameworks and models to distinguish their approaches and guide their work. Each is framed and driven by their program mandate's scope and focus, their health system of interest (public, private, social franchise, social insurance), and by their specific goals. Improving and assuring quality of care is a shared goal of many health care program frameworks, but is typically part of a broader results agenda. These frameworks therefore incorporate elements of quality of care among the requisite conditions and interventions comprising the theories of change that guide their programs.

\section{Maximizing Access and Quality Initiative (MAQ)}

In 1993 USAID launched the Maximizing Access and Quality Initiative, or MAQ, for FP and other RH services, to promote quality services and remove barriers preventing people from using them. This was done by fostering collaboration among USAID missions, cooperating agencies, and other partners to identify and expand the application of lessons and evidence-based interventions. MAQ embraced the Bruce quality of care framework and supplemented it with modifications including quality standards, protocols and guidelines, consideration of gender relations and of clients' access to services, and addressing the effects of incentives and disincentives ${ }^{30}$.

MAQ promoted the following principles to enhance quality:

- Offer a range of contraceptive methods and services;

- Treat clients with respect and developing counseling and services according to their knowledge, needs, preferences, and concerns;

- Teach clients how to use their chosen methods correctly; and

- Inform clients about common side effects and how to manage them, and assure clients that they can switch methods if they want ${ }^{31}$.

\section{WHO's Health System Strengthening Framework}

In 2007 WHO issued a health system conceptual framework as part of its health system strengthening strategy ${ }^{32}$, with six building blocks of health systems intended to lead to four goals, or desired outcomes, that define improved health system performance, shown in Figure 2 (following page). In this schema, quality is an implied attribute of three of the building blocks: service delivery, information, and medical products and technologies. It is also an explicit, intermediate goal of health personnel and health system performance. Surprisingly, WHO does not define quality in its Health Systems Strengthening Glossary ${ }^{33}$. 
FIGURE 2 THE SIX BUILDING BLOCKS OF A HEALTH SYSTEM: AIMS AND DESIRABLE ATTRIBUTES

SYSTEM BUILDING BLOCKS

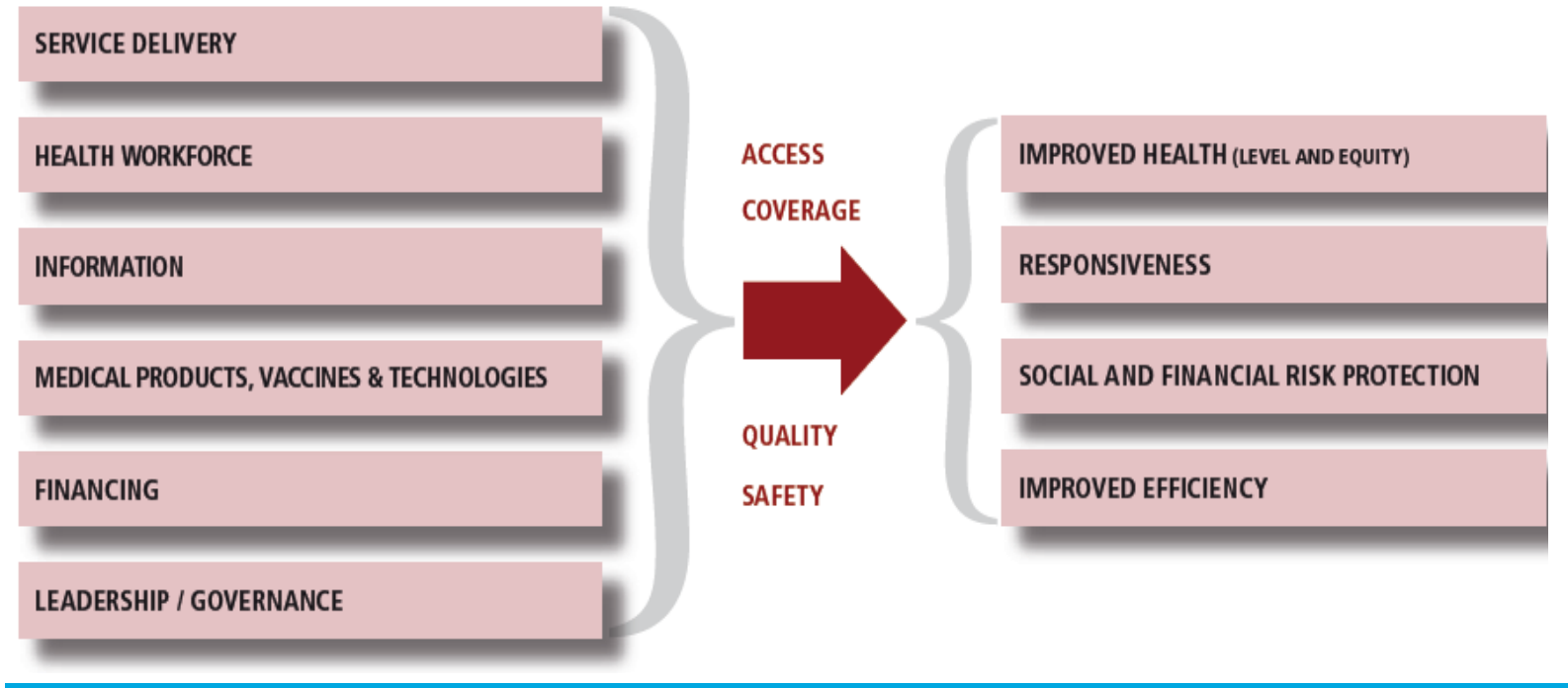

\section{Situation Analysis}

The Population Council's Situation Analysis Approach to assessing FP and RH services offered the first systematic methodology and data collection tool for essential information about the status of infrastructure and equipment, and of program operations at individual service sites. Situation Analysis studies have been conducted in dozens of countries since the first one in Kenya in 1989, providing critical data that have informed performance improvement efforts. Quality is a component of the Situation Analysis Conceptual Model (Figure 3). The model adopts the Bruce quality framework.

\section{FIGURE $3^{34}$ SITUATION ANALYSIS CONCEPTUAL MODEL FOR CONTRACEPTIVE SERVICES}

\section{Readiness}

- Contraceptives and supplies

- Facilities and equipment

- Staff training and attitudes

- IEC materials

- Supervision and management

- Policies and procedures

\section{Quality}

- Choice of methods

- Information exchange

- Interpersonal relations

- Technical competence

- Mechanisms to encourage continuity

- Appropriate constellation of services
Impact

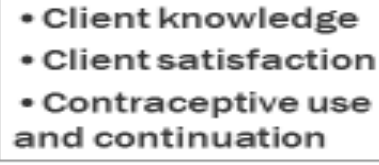

- Client knowledge

- Client satisfaction

- Contraceptive use and continuation 


\section{EngenderHealth's Holistic SEED Programming Model and Fundamentals of Care}

At the center of this comprehensive program model is the overall goal of meeting clients' SRH and reproductive intentions. This is achieved by the interaction among three interrelated and mutually supportive program components: supply (factors related to service capacity and performance), enabling environment (policy, resource and cultural contexts), and demand (community demand for and use of services) ${ }^{35}$. The underlying premise is that the availability and quality of services, the systems and environments supporting them, and people's knowledge and use of those services are all interrelated and must be addressed in a comprehensive and coordinated manner.

Quality is one of several factors in the supply component of this programmatic vision. EngenderHealth encapsulates the essential elements of quality of care in what it calls the Fundamentals of Care ${ }^{36}$ :

- Informed choice, with informed and voluntary decision making;

- Clinical safety, with skilled providers working in an appropriately equipped and well managed service site, adhering to evidence-based standards, guidelines and protocols and infection prevention procedures; and

- A mechanism for ongoing quality assurance and quality improvement based upon clients' rights and staff needs (a modification of the Huezo and Diaz Quality of Care Framework).

FIGURE 4 ENGENDERHEALTH'S FAMILY PLANNING PROGRAMMING MODEL

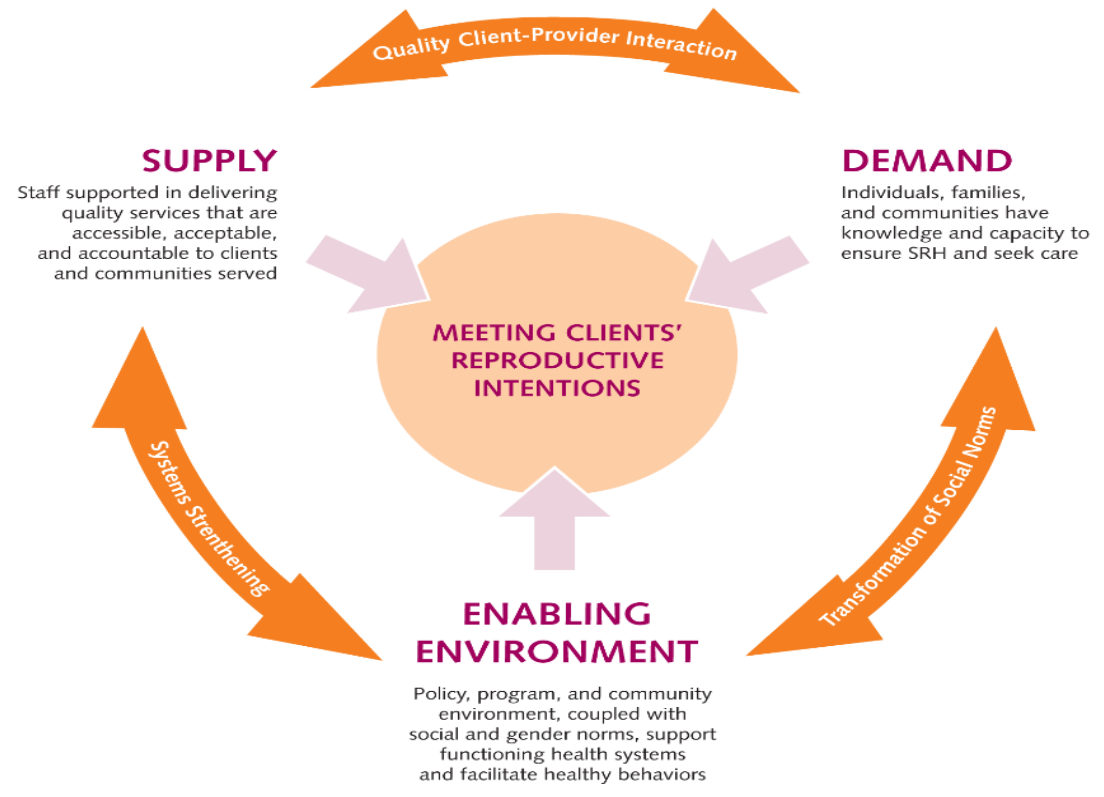

\section{Marie Stopes International}

Quality is a critical output in Marie Stopes International (MSI)'s programming model, and is defined both through clinical attributes (safety, effectiveness, efficiency) and client experience. MSI collects data from multiple sources to monitor client satisfaction with such [rogram elements as service hours, facility cleanliness, waiting times, friendliness and respectfulness of staff, level of privacy during consultation and treatment, information provided, the treatment or service itself, and its cost ${ }^{37}$. MSI also focuses on equity, monitoring whom they serve and whether they are reaching desired demographic groups. 


\section{Quality of Care at the centre}

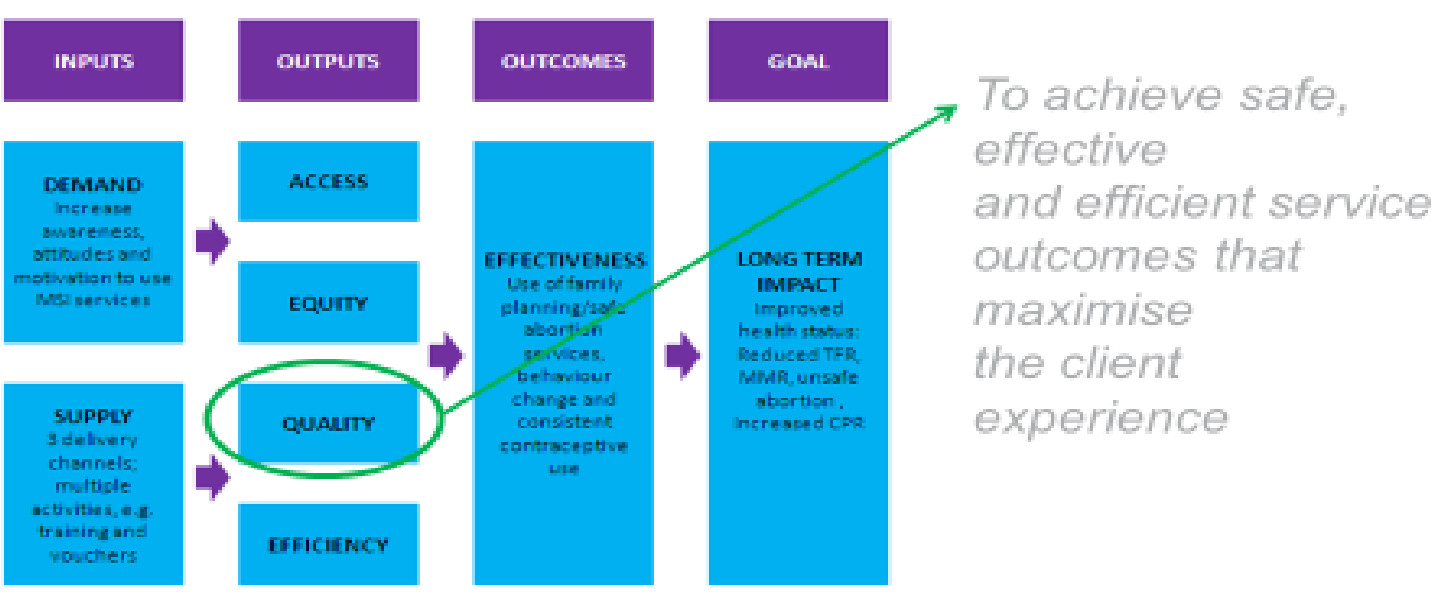

These diverse models position quality in a range of organizational contexts. They reflect diverse missions and goals, and span a systems perspective, a research perspective and a few examples of the service delivery perspective. As is true for definitions of quality, all of these models add conceptual value to the discussion. A comparative analysis of their relative merits and weaknesses in actual practice is beyond the scope of this paper. However, they serve to show how quality fits into a more complete programmatic picture, which begs the question, What investments are needed to improve and sustain quality in FP? This leads to a bigger question: Is the focus on quality of care in service delivery sufficient or do we need to take a broader programmatic view and apply a more inclusive construct to define desired results and determine what to invest in and monitor? 


\section{How Do Quality and Service Delivery Models Relate to a Rights-based Approach?}

As with quality of care, and FP service programs more broadly, numerous frameworks and guidance documents define a rights-based approach (RBA) to health care, with a few specific to FP. Their common underpinning is the centrality of the dignity of the individual, along with the entitlements, freedoms, and protections, or rights, due by virtue of being human. The goal of this approach is for all people, everywhere, to realize these rights. Rights-based health care commits to respecting, protecting, and fulfilling specific human rights by applying rights-related principles in all phases of health care planning, service delivery, and program monitoring and evaluation. It entails explicit responsibility and accountability of governments and programs to enable individuals' realization of specific human rights to health, and to ensure redress for those whose rights are violated. This approach roots health care programs in ethics and social justice, valuing human dignity, agency, equity, and equality in addition to quality, stressing programs' accountability to the people they are meant to serve. The human rights-based approach thus provides a broader concept than quality of care for program design, monitoring, and improvement, and health care investments.

\section{HUMAN RIGHTS THAT PERTAIN TO FAMILY PLANNING PROGRAMS}

The Right to Health is a cornerstone of a rights-based approach to all health care, including FP. As enshrined in General Comment 14, Article 12 of the International Covenant on Economic, Social and Cultural Rights, it includes the right to control one's health and body, including sexual and reproductive freedom, to be free from torture and non-consensual medical treatment and experimentation, and the right to the equality of opportunity for the highest attainable level of health ${ }^{7}$. General Comment 14 also states the importance of a population's participation in all health policy decisions, at all administrative levels, as well as the importance of non-discrimination at health facilities, for goods and services, thereby establishing two required principles.

In addition to quality, the Right to Health identifies three other essential conditions of health services governments are obligated to ensure: availability, accessibility, and acceptability (with quality included, "AAAQ" stands for the Right to Health). In FP programs, this means:

\section{Available:}

- A broad choice of methods offered;

- Sufficient numbers, with need-based distribution, of functioning service delivery points;

- Continuous contraceptive security;

Accessible: facilities, goods, and services accessible to all, especially the most vulnerable or marginalized:

- Physical and geographic accessibility, including adequate access to buildings for those with disabilities;

- Economic accessibility, with affordability for all; based upon the principle of equity, service costs should be proportionate to patients' incomes;

- Information accessibility, in languages and terms people can understand;

\section{Acceptable:}

- Respectful of medical ethics;

- Culturally appropriate;

- Sensitive to gender and life cycle requirements; and

- Designed to respect confidentiality. 
Of the rights articulated in the plans of action of the 1994 ICPD and the Beijing Conference on Women, specific to SRH is the right "of all couples and individuals to decide freely and responsibly the number, spacing and timing of their children and to have the information and means to do $\mathrm{so}^{10}$," and the right to "have control over and decide freely and responsibly on matters related to their sexuality, including sexual and reproductive health, free of coercion, discrimination and violence $39 . "$

In 1994, the International Planned Parenthood Federation (IPPF) published a Charter of Sexual and Reproductive Rights that identifies 12 internationally recognized human rights that apply to SRH and FP40 (this was embellished in 2008 when IPPF published a Declaration of Sexual Rights to address emerging issues and areas of concern).

TABLE 2 Sexual and reproductive rights identified by IPPF (1994)

The right to life

The right to liberty and security of the person

The right to equality, and to be free from all forms of discrimination

The right to privacy

The right to freedom of thought

The right to information and education

The right to choose whether or not to marry and to found and plan a family

The right to decide whether or not to have children

The right to health care and health protection

The right to the benefits of scientific progress

The right to freedom of assembly and political participation

The right to be free from torture and ill treatment

In 2008, Erdman and Cook categorized reproductive rights into three categories ${ }^{41}$ :

- Rights related to reproductive self-determination ;

- Rights to SRH services, information, and supplies; and

- Rights to equality and non-discrimination.

Their typology has been referenced in rights-based frameworks.

\section{RIGHTS-BASED PRINCIPLES}

A rights-based approach is characterized not just by the human rights a program is obligated to respect, protect and fulfill, but by the application of certain principles in how programs are planned, implemented, monitored, evaluated and held accountable. Commonly accepted rights-related principles are captured in the acronym PANEL-for Participation, Accountability, Non-discrimination and equality (meaning both equal treatment for all those being served, and concerted efforts to reach those not being served), Empowerment, and Links to treaty bodies the government has signed, which makes commitments legally binding and defines international standards.

Different entities, like WHO and the FP2020 Rights and Empowerment Working Group, have generated other lists of rights-related principles as a basis for their guidance and recommendations. These are described in the following section.

\section{RIGHTS FRAMEWORKS AND GUIDANCE}

Key rights-based approach (RBA) frameworks for development and health in general, and FP programs specifically include: 
CARE's rights-based approach to programming 42 focuses explicitly on achieving the minimum conditions for all people, including poor, displaced, and war-affected individuals, to live with dignity, which they equate with the realization of individuals' human rights. It supports interventions that empower people to claim and exercise their rights and fulfill their responsibilities. CARE's RBA foundational principles and practices are:

- Affirming people's right to participate in decision-making processes that affect their lives;

- Seeking to address the roots of poverty and human suffering;

- Refusing to tolerate discrimination and inequity; and

- Holding ourselves and others accountable for respecting and helping to protect and fulfill human rights.

The United Nations has defined its human rights approach in terms of its goal, process, and outcomes 43 :

- Goal: All programs of development cooperation, policies and technical assistance should further the realization of human rights as laid down in the Universal Declaration of Human Rights and other international human rights instruments;

- Process: Human rights standards and principles guide all development cooperation and programming in all sectors and phases of the programming process; and

- Outcomes: Development cooperation contributes to the development of the capacities of "duty bearers" to meet their obligations and/or of "rights-holders" to claim their rights.

This approach applies to all domains under the purview of all UN agencies. UN's RBA aims to fulfill the right to health and other health-related human rights for people everywhere, with a focus on eliminating all forms of discrimination and gender mainstreaming.

As part of the UN system, WHO takes a human rights-based approach to health. In 2014 they issued guidance to help policymakers, managers, providers and other stakeholders ensure human rights dimensions are systematically and clearly integrated into the provision of contraceptive information and services ${ }^{12}$. The guidance recommends evidence-based interventions supporting nine human rights components and principles, or standards:

- Non-discrimination in provision of contraceptive information and services;

- Availability of contraceptive information and services;

- Accessibility of contraceptive information and services;

- Acceptability of contraceptive information and services;

- Quality of contraceptive information and services;

- Informed decision making;

- Privacy and confidentiality;

- Participation; and

- Accountability.

As the standard WHO guideline development process was used to generate recommendations, their recommendations are firmly evidence-based.

UNFPA and WHO recently developed technical guidance for operationalizing a human rights-based approach to contraceptive services consistent with the UN system's broad framework. This new, joint document, Ensuring Human Rights Within Contraceptive Service Delivery Implementation Guide (2015)44, melds recommendations from WHO's guidance for rights-based contraceptive information and service and UNFPA's 2012-2020 FP strategy. Intended as a companion to WHO's guidance and recommendations, the guide also reflects UNFPA's commitment to gender equality and human rights central to its Strategic Plan for 2014 to 2017. Intended to help mid-level policymakers, program managers, and implementers involved with FP service provision in all settings translate human rights standards into concrete action, the guide is structured around the nine human rights standards articulated in the WHO guidance. In the document, quality of care subsumes the six elements of quality in the Bruce framework plus standards of care, acceptability, client feedback, privacy and confidentiality, and gender sensitivity. The guidance offers key 
considerations and action points for ensuring informed decision making, privacy and confidentiality, and quality assurance.

Shortly after WHO issued its guidance, the Rights and Empowerment Working Group of FP2020 elaborated on 10 rights principles that are necessary for realizing RBA for FP programs. The purpose of this effort was to establish a common understanding of what these principles mean within FP programs. Through some different wording and grouping, they cover all the principles identified in the WHO guidance to which they add agency and autonomy, empowerment, equity, choice, transparency and voice ${ }^{45}$. For each principle, the guidance offers a definition, a broad statement of what should be done (without implementation guidance), a statement of what should be measured and another about markets and marketing strategies. Its definition of quality borrows from previously established definitions:

"Individuals have access to contraceptive services and information of good quality which are scientifically and medically appropriate. Quality of care is a multifaceted element that includes but is not limited to: a full choice of quality contraceptive methods; clear and medically accurate information, including the risks and benefits of a range of methods; presence of equipped and technically competent providers; and client-provider interactions that respect informed choice, privacy and confidentiality, and client preferences and needs ${ }^{45}$."

Voluntary, Rights-based Family Planning (VRBFP) Conceptual Framework: With support from the Gates Foundation following the FP 2012 Summit, Hardee et al. developed the VRBFP framework, a vision of an ideal, holistic rights-based FP program in all its richness and complexity. The framework depicts a program designed to achieve both public health (i.e. FP) and rights outcomes, which it regards as mutually supportive. It merges elements and principles from public health, FP, holistic health care programming, quality of care, informed choice, and human rights into a single, unifying framework for guiding FP design, monitoring, and investments. The framework bridges the gap between theory and practice by offering a practical, programmatic approach for operationalizing human rights within FP programs. It is structured as a logic model that recognizes the country context and depicts action at four health system levels: policy, service delivery, community, individual; and identifies key program elements that need to be addressed at each level, encompassing the whole program, not just service delivery. Quality is explicit as both an attribute of inputs and as an expected output. Every program element is linked to the human right or rights it supports, including the right to health and reproductive rights as categorized by Erdman and Cook ${ }^{41}$.

The excerpt of the framework in Figure 6 (following page) shows that it blends elements of Comment 14, Article 12 of the Right to Health and of the Bruce quality framework in its definition of quality.

A companion Users' Guide ${ }^{46}$ supports stakeholders in applying the framework to increase awareness and understanding of how to make rights concrete and actionable in FP programs; to assess, strengthen and design programs; to create strategic partnerships and identify common ground between the public health and rights communities, and to monitor and evaluate programs and hold them accountable. It offers stepby-step guidance for transforming abstract rights concepts into concrete, programmatic action steps.

As demonstrated by these frameworks, a rights-based approach centers around the individual client, or potential client, rather than a health system or providers, empowering and engaging people's exercise of self-determination for their health and fertility, and eliminating policy and program barriers and practices, including all forms of discrimination that could block any person's rights fufillment. While it includes quality of care, it extends beyond medical science: It is more of an ethical than medical model. A rights-based approach is a broader programmatic construct than quality of care, which is essentially a service delivery construct, and reflects all components of health care systems and programs, including the policy and cultural context and both supply and demand. A rights-based approach applies both to those served and those not served, unlike quality of care, and is characterized by participation, individual agency, and equity, with special attention to marginalized and vulnerable groups, as well as program accountability. Since a rights-based approach protects medical safety and effectiveness of services in addition to other human rights for health care, it is appropriate to maintain a focus on service quality within the broader rights approach rather than limiting the program focus to assuring and improving quality. 


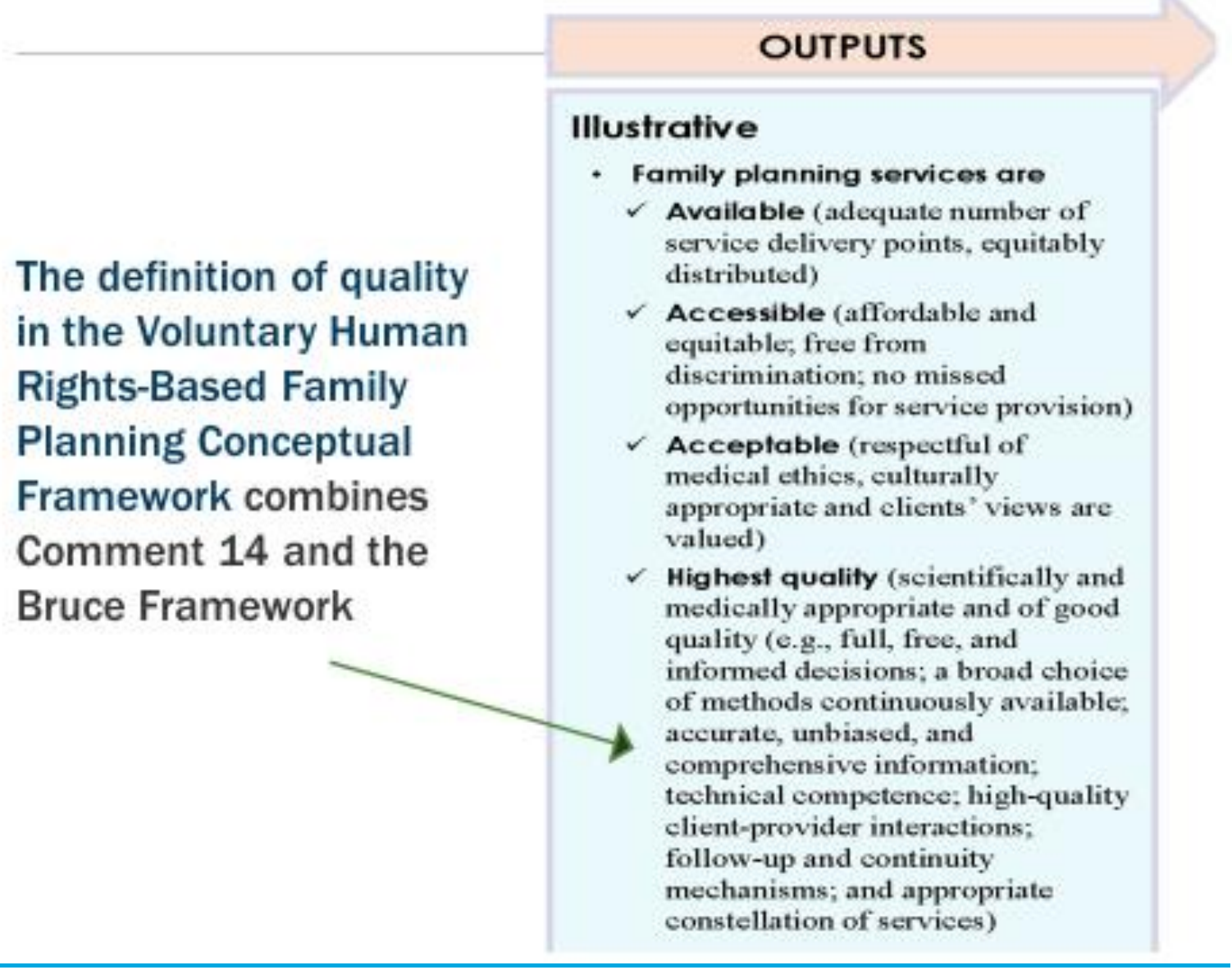

\section{WHAT ADDITIONAL OR DIFFERENT INPUTS DOES A RIGHTS-BASED APPROACH REQUIRE?}

The good news is that applying a rights-based approach to FP programs does not require totally overhauling programming as we know it or adding a lot of work. Existing efforts to ensure informed and voluntary FP, quality of care and method choice, efforts to expand access, to serve youth, and promote gender equality contribute significantly to rights-based FP.

We need to continue and to build upon the progress made in these areas, not to drastically change what we do. Family planning programs and rights activists use different terminologies, but many of their principles and goals are the same. We do need to examine future needs for FP services in the context of the Sustainable Development Goals and universal health coverage to better understand where investments by countries, donors, and health systems will be needed to achieve desired outcomes. In the coming years, we will have to examine both client and health system needs and design responses through the lens of respecting the dignity of individuals and protecting and fulfilling their rights. This may result in the identification of different programmatic responses involving changes in how we do things, adding program enhancements, or engaging new partners, and we need to be more intentional about community and individual participation and empowerment, equity, and accountability.

Based on a field test of the Users' Guide for the Voluntary, Rights-based Family Planning Framework in Kampala in 2014, we recognize that the progressive realization of human rights can be advanced by 
modifying existing FP program activities and practices even within existing resources. Participants in the field test identified a number of steps they could take within their existing work plans ${ }^{48}$ :

- Sharing information about a rights-based approach with colleagues and implementing partners in working group and coordinating committee meetings;

- Adding human rights to the agenda of routine meetings of all FP fora, including District Health Officer meetings;

- Incorporating human rights and health personnel responsibilities into all capacity building, supervision, monitoring and quality assurance activities;

- Making respect for and protection and fulfillment of clients' human rights an explicit performance expectation, and building these behaviors into motivation mechanisms; and

- Reviewing all policies, strategies, guidelines and training materials to identify needs for revision to align them with rights-based principles.

Additional resources could support more orientations, materials revision, community engagement, badly needed research and rigorous program evaluation, plus documentation and dissemination.

The guidance documents cited in this paper offer recommendations for how to operationalize a rights-based approach in FP programs. Here are ten critical inputs:

- Increasing rights literacy for both consumers and health care staff;

- Increasing meaningful community participation in service design, implementation, and monitoring;

- Partnering strategically with civil society and rights and gender groups to inform and empower communities; seizing opportunities to add human rights in FP to the agenda of other initiatives, working groups, watchdog entities and events;

- Making supportive behaviors for respecting, protecting and ensuring rights explicit in staff performance expectations and reviews;

- Monitoring who the program is and is not serving and making concerted efforts to reach vulnerable and marginalized groups, informing them of their rights and supporting their ability to exercise them;

- Supporting interventions that strengthen equity and individual empowerment, i.e. the ability of all women and girls to make and act upon their FP decisions with freedom of choice and action, and equitable access to quality FP information, services and supplies;

- Making human rights explicit in program monitoring and evaluation and developing monitoring indicators and methodologies that generate data at both the aggregate level of the program or population and at the perspective of the individual client's experience;

- Reviewing policies, program objectives, service delivery guidance, official and unofficial communications for focus and language, and adjust as needed to make sure they are client-centered;

- Strengthening accountability and redress mechanisms; investing in treaty monitoring bodies, watchdog groups and processes to identify and address rights violations; acting swiftly when alleged problems arise; creating legal precedents that establish credible accountability; publicizing abuses and actions taken; and

- Applying and evaluating a rights-based approach to build an evidence base about challenges, effective practices and added value.

Moreover, a recent systematic review of the literature on voluntary, right-based FP programs found a dearth of literature linking public health and rights-based outcomes ${ }^{49}$. By deconstructing the concept of a rightsbased approach into its constituent elements from a program perspective, however, it found substantial evidence of the impact of specific program interventions on rights outcomes-for policy and governance, service quality and access, community engagement, and individual knowledge and empowerment.

Additional evidence of the added value of a human rights approach was documented in a recent WHO study of the effect of explicitly human rights-shaped interventions on women and children's health outcomes ${ }^{50}$. The study, in four countries, found that an explicit focus on human rights contributed to health-related gains 
in four different kinds of health programs, including increased access to modern contraception (Brazil), increased access to emergency obstetric care (Nepal), reductions in early childhood mortality (Malawi), and increased vaccination coverage (Italy). More such studies are needed to build a more robust evidence base on the impact and benefits of a rights-based approach to FP.

Yet it is safe to say that while a rights-based approach covers quality of care, the inverse is not true. Examples of where the narrow focus on quality fails to address the larger issues of human rights in health care include:

- With a narrow quality focus, client voice and participation (as well as those of potential clients) are often absent in both the planning of new services and evaluation of existing efforts;

- When the focus is on the medical safety of clients served with little or no attention to the profile of who is and is not being served, the issue of equity is often overlooked; focusing on quality for clients who avail themselves of services does not protect the rights of those who do not have access to services, for whatever reason (stigma, distance, ethnicity, cost);

- Quality of services does not address the policy environment in which those services are provided, which could limit method choice and/or create provider bias that compromises clients' full, free, and informed choice; such policies as client eligibility criteria, range of methods offered, method-specific promotion, numerical performance targets; and provider incentives can compromise clients' human rights even in the case of good clinical services;

- Quality does not in itself redress the problems of gender inequality; some would maintain that focusing services only on women ensures that they carry a larger burden for RH outcomes, leaving men without responsibility for their behavior or with alternatives to contribute to women's health. In and of itself access to quality FP services does not lead to women's empowerment; while it is necessary, it is not sufficient; the theory of change is complex; and

- The themes of governance and accountability are poorly understood and often addressed haphazardly at the health system level; both are rarely found in the analysis of quality of care, but are necessary for sustainable solutions to shortfalls in quality (disrespect and abuse of clients), and for programs that seek to protect and fulfill the rights of all clients and potential clients (e.g. client feedback mechanisms, protocols to investigate alleged rights violations, protocols to manage confirmed violations and redress mechanisms for the aggrieved).

It is worth noting that the health and rights communities have traditionally worked on parallel tracks and at times have been at odds with one another, particularly over FP policies and practices that impinge on individual autonomy, equity, free and informed choice, method options, and quality FP information and services. There is an inherent tension in applying a rights-based approach to health care since human rights and public health does not share a common ethos. While the goal of the public health system is to achieve the greatest good (i.e. the best quality health outcomes and status) for the greatest number, a rights-based approach focuses on individual dignity, entitlements, and empowerment

Yet the public health approach and the rights approach need not stand in opposition to one another. They share common ground and are actually complementary, rather than contradictory. Combining them can benefit both individuals and programs: A rights-based approach can enhance quality and health outcomes while also meeting desired rights outcomes. This approach may result in the identification of new or different program needs and solutions and different partnerships that extend beyond the public health community. 


\section{Discussion}

Family planning is an elective, preventative health care service related to sexuality and fertility, burdening it with religious and cultural sensitivities, gender and power dynamics, and population implications that distinguish it from other health care services. The concept of quality of care, derived from health care in general, has been applied and adapted to FP, and retains a central focus on medical safety. Some definitions of this adaptation, however, incorporate attributes borrowed from other rights and rights-based principles including accessibility, availability, acceptability, choice, information, privacy, confidentiality, gender considerations, dignity, and cultural acceptability. Thus the definition of quality in FP has expanded beyond the attributes of clinical practice, medical supplies, and equipment to include counseling and communications, other dimensions of service delivery, and broader program elements. How quality is defined within and among organizations varies considerably, which hinders prioritization, effective partnerships, and consistent monitoring and measurement within and across health systems.

Table 3 (page 21) provides the elements of quality from 15 different constructs, although with varying terminologies that, in some cases, make intent hard to discern, but every effort has been made to group like elements and distinguish those with distinct meanings. What is clear is that the Bruce framework and Comment 14, Article 12 of the Right to Health form the foundations of most operational definitions. While Comment 14 cites quality as one of four equally weighted attributes of health care information, services, and commodities to which people are entitled as a human right, several definitions include the other attributes (availability, accessibility, acceptability) as elements of quality. A couple of definitions explicitly include consideration of gender relations as part of quality; a few stipulate effectiveness and efficiency as elements of quality; one framework emphasizes prevention and treating the whole individual; and another addresses incentives and disincentives.

Quality of care and a rights-based approach are related, but not interchangeable, constructs. The problem of blurring their distinguishing characteristics is that, in the absence of agreement for the meaning of each terminology, discourse gets confused and neither concept gets adequate attention.

The focus on the essentials of quality of care in FP has diminished in recent years, for many reasons including the belief it has been mainstreamed, along with shifts in focus toward health system strengthening and contraceptive security, lack of clarity of what quality entails in the move towards rights-based development, or insufficient evidence that quality of care leads to increased and sustained FP use. Poor medical quality and ineffective counseling remain critical issues in FP and other SRH programs. Deficiencies persist with serious consequences for both individuals and programs. Improving and assuring quality of care is a legal, ethical, and practical imperative. States have committed themselves to protect and fulfill quality as an essential element of the right to health. Moreover, quality in FP service delivery is instrumental in achieving other desired outcomes that benefit women, children, programs, and communities.

Returning to the basics of quality of care and framing it within a human rights context, rather than expanding the definition of quality to include rights elements, would increase clarity and maintain focus on the critical elements of service delivery. While quality is an element of the right to health, on its own it provides a narrow portal to the constellation of health care program responses necessary for protecting and fulfilling people's human rights. The broader rights-based approach, which includes quality, affords a more appropriate foundation for health care programming. 


\section{Conclusion}

Conflation of the constructs of quality of care and a rights-based approach has led to confusion and insufficient attention to important program elements. A common definition for FP quality of care, limited to the client's service delivery experience, is needed. The widely accepted Bruce quality framework, which has guided international FP for 25 years, could continue to serve the field well. Although desired elements of quality such as safety and assuring client privacy and dignity are not explicit in the wording of the framework's six elements, as in other definitions of quality, they are implied by their phrasing and are in fact articulated within the paper. Some rewording to highlight these essentials is advisable.

More is needed, however. As noted by experts convened for the subject of contraceptive choice in 2012, "Programs must focus on quality, including counseling; however, this is not sufficient to ensure that women are empowered to exercise their rights and choices 51 ." Equitable access to quality FP information and services and contraceptive choice for informed and voluntary decision making are human rights, but are not yet a reality for millions of women and girls. Governments have committed to fulfilling these rights, and donors, governments, programs and civil society leadership need to be accountable for respecting, protecting, and fulfilling them. Progressive realization of rights, including quality improvement, in FP programs can be achieved in time through sustained effort within available resources by taking a different approach, thinking in terms of clients, rather than systems, services or methods, by making people's dignity and needs central to efforts, and by engaging clients in program planning, implementation, and evaluation.

A rights-based approach seeks to ensure no one is pressured or induced into accepting a service they do not want, that everyone has access to the information and services they desire, and that services are of the best possible quality. It calls for donors and governments to revisit policies that could potentially compromise human rights, including eligibility criteria, numerical performance targets, incentive payments, and methodspecific promotion. It involves concerted effort and investment targeted at reaching the most vulnerable and marginalized with information and services. It also calls for expanding method choice and supporting effective client counseling to protect clients' free and informed decisions, as well as rights literacy training for providers, supervisors, and community members, along with community engagement. In a RBA respecting individual clients' dignity and autonomy is rewarded. Accountability and redress mechanisms are strengthened. The shift toward rights-based FP programming needs to be bolstered by the systematic application and evaluation of a RBA, plus documentation and dissemination of its results, as priorities on the global research agenda.

The expected benefits include greater community trust in the health care system, increased client satisfaction and service use, better health outcomes, and improved program sustainability. While improving and assuring quality contributes to achieving these desired results, experts convened by the Population Council and Packard Foundation for the Measuring and Monitoring Quality of Care Meeting in December 2014 concluded, "Clients' rights to the highest quality of care should be the underlying principles for an enhanced focus on investing in and measuring quality...our focus should not be instrumentalist ${ }^{52}$."

The rationale for an explicit and comprehensive rights-based approach is ethical and legal: It is the right thing to do, and governments have made legally binding commitments to respect, protect, and fulfill their citizens' human rights. Evidence also indicates that a rights-based approach enhances public health outcomes, and if applied comprehensively, it could be a low cost, high impact "game changer." If donors embrace, fund, and hold governments accountable to the fullness of a FP rights-based approach, with explicit focus on quality of care, and if governments and NGOs embed rights principles in how they plan, implement, and monitor their FP programs, assuring access without discrimination, medical safety, and full, free, informed choice for all, they would transform the path to their ambitious FP2020 goals, and eventually universal health service coverage called for by the Sustainable Development Goals for 2030. 


\begin{tabular}{|c|c|c|c|c|c|c|c|c|c|c|c|c|c|c|c|}
\hline \multirow[b]{2}{*}{ Elements } & \multicolumn{6}{|c|}{ Quality Frameworks } & \multicolumn{4}{|c|}{$\begin{array}{l}\text { Service/Program } \\
\text { Models and } \\
\text { Frameworks } \\
\end{array}$} & \multicolumn{5}{|c|}{$\begin{array}{l}\text { Rights-based } \\
\text { Frameworks }\end{array}$} \\
\hline & 운 & 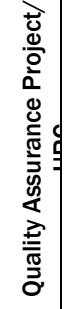 & 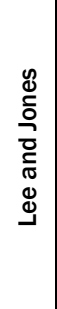 & 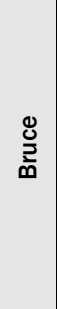 & 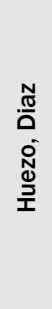 & 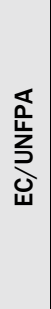 & 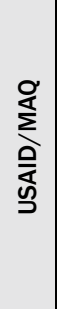 & 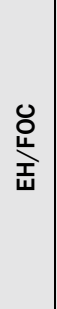 & $\bar{\Sigma}$ & 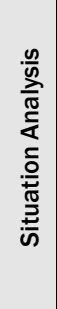 & 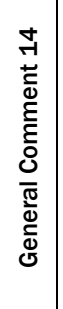 & 운 & 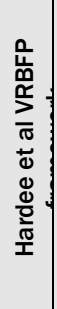 & 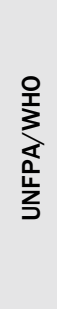 & ণัे \\
\hline Based on medical science, is evidence-based; safe & $\bullet$ & ○ & - & & ○ & & - & ○ & - & & ○ & - & - & ○ & - \\
\hline $\begin{array}{l}\text { Skilled and competent medical personnel whose } \\
\text { needs are met (training, supervision, infrastructure, } \\
\text { supplies, respect, motivation) }\end{array}$ & & & & ○ & ○ & ○ & - & ○ & & ○ & - & - & - & 0 & ○ \\
\hline Effective & 0 & 0 & & & & & & & 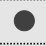 & & & & & & \\
\hline Efficient & 0 & 0 & & & & & & & 0 & & & & & & \\
\hline Emphasizes prevention & & & 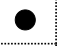 & & & & & & & & & & & & \\
\hline Public and practitioner cooperation & & & $\bullet$ & & & & & & & & & & & & \\
\hline Treats the whole individual & & & 0 & & & & & & & & & & & & \\
\hline $\begin{array}{l}\text { Continuing physician and patient relationship, good } \\
\text { interpersonal relations }\end{array}$ & & $\bullet$ & - & 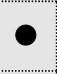 & ○ & ○ & ○ & & & $\bullet$ & & - & - & - & ○ \\
\hline Follow up mechanisms; continuity of care & & ○ & & ○ & - & • & - & & & 0 & & - & - & O & ○ \\
\hline Coordination with social welfare & & & - & & & & & & & & & & & & \\
\hline $\begin{array}{l}\text { Coordinates all medical services; links to other } \\
\text { services; effective referral systems }\end{array}$ & & & ○ & & & - & & & & & & & & & \\
\hline $\begin{array}{l}\text { Appropriate constellation of services (convenient, } \\
\text { acceptable, responsive to health concepts and } \\
\text { needs) }\end{array}$ & & & & $\bullet$ & & & $\bullet$ & & & • & & - & - & - & \\
\hline Applies to all people, equitable, same for everyone & - & & - & & & & & & ○ & & & & & & \\
\hline Offers broad choice of methods & & & & 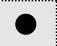 & 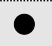 & & ○ & & & $\bullet$ & & - & - & 0 & ○ \\
\hline Information/ informed choice and decision making & & & & 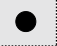 & 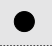 & 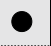 & 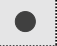 & - & 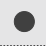 & 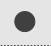 & & 0 & 0 & O & ○ \\
\hline $\begin{array}{l}\text { Availability of approved, unexpired drugs and } \\
\text { equipment }\end{array}$ & & & & & & • & & & & & - & & - & & \\
\hline Good physical infrastructure; cleanliness & & - & & & & - & & & ○ & & & & & & \\
\hline Accessible (geographical, cost) & ○ & - & & & - & - & ○ & & - & & & & & & \\
\hline Privacy and confidentiality protected & & & & & ○ & & & & ○ & & & O & & 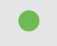 & 0 \\
\hline $\begin{array}{l}\text { Assures dignity and comfort (physically, culturally, } \\
\text { reasonable waiting time) }\end{array}$ & & $\bullet$ & & & $\bullet$ & & & & $\bullet$ & & & & & & \\
\hline $\begin{array}{l}\text { Client recommendations, opinions, perceptions } \\
\text { of quality }\end{array}$ & & & & & $\bullet$ & & & & ○ & & & & & - & \\
\hline $\begin{array}{l}\text { Culturally and personally acceptable, client- } \\
\text { centered, individualized }\end{array}$ & - & & & & & & & & $\bullet$ & & - & - & & - & 0 \\
\hline $\begin{array}{l}\text { Quality assurance processes, including medical } \\
\text { standards and client feedback, incorporated }\end{array}$ & & & & & & & $\bullet$ & $\bullet$ & & & & & & & \\
\hline Considers gender relations & & & & & & & 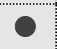 & & & & & & & 0 & \\
\hline $\begin{array}{l}\text { Insertion and removal services and counseling } \\
\text { on side effects for LARCS in same locality }\end{array}$ & & & & & & & & & & & & & & & \\
\hline Safe, potable water & & & & & & & & & & & O & 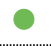 & & & \\
\hline Adequate sanitation & & & & & & & & & & & 8 & 8 & & & \\
\hline Addresses incentives and disincentives & & & & & & & ○ & & & & & & & & \\
\hline
\end{tabular}




\section{References}

1. Lee, R.I., L.W. Jones. 1933. The Fundamentals of Good Medical Care. Chicago: University of Chicago Press.

2. Donabedian, A. 1966. Evaluating the Quality of Medical Care. Milbank Memorial Fund Quarterly 44(3,2): 166-203.

3. Bruce, J. 1990. Fundamental Elements of the Quality of Care: A Simple Framework. Studies in Family Planning 21(2): 61-91.

4. Huezo, C., S. Diaz. 1993. Quality of Care in Family Planning: Clients' Rights and Providers' Needs. Advances in Contraception 9(2): 129-139.

5. University Research Corporation. Quality Assurance Project Overview. www.urc_chs.com. Accessed 16 January 2015.

6. Population Council. 2002. What About Us? Bringing Infertility into Reproductive Health Care. Quality/ Calidad/Qualité 13.

7. United Nations Committee on Economic, Social and Cultural Rights. 2000. General Comment 14, Article 12 of the International Covenant on Economic, Social and Cultural Rights. Report on the Twenty-Second, Twenty-Third and Twenty-Fourth Sessions, Economic and Social Council Official Records 2001, Supplement 2.

8. United Nations. 1968. Proclamation of Teheran. Final Act of the International Conference on Human Rights. Article 16, UN Doc A/CONF/32/41.

9. United Nations. 1969. General Assembly Resolution 2542, Declaration on Social Progress and Development. UN Doc A/7630.

10. United Nations. 1994. Report of the International Conference on Population and Development. Article 7.3, UN Doc A/CONF 171/13.

11. United Nations Programme of Reform. 1997.

12. WHO. 2014. Ensuring Human Rights in the Provision of Contraceptive Information and Services: Guidance and Recommendations.

13. FP2020 Rights and Empowerment Working Group. 2014. Principles for Family Planning.

14. Hardee, K., K. Newman, L. Bakamjian, J. Kumar, S. Harris, M. Rodriguez, K. Willson. 2013. Voluntary Family Planning Programs that Respect, Protect, and Fulfill Human Rights: A Conceptual Framework. Washington, DC: Futures Group.

15. WHO Office of the High Commissioner for Human Rights (OHCHR). 2008. The Right to Health. Factsheet 31.

16. Darroch, J.E. and S. Singh. 2013. Trends in Contraceptive Need and Use in Developing countries in 2003, 2008 and 2012: An Analysis of National Surveys. Lancet 381(9879): 1756-1762.

17. Jain, A.K., S RamaRao, J. Kim, M. Costello. 2012. Evaluation of an Intervention to Improve Quality of care in family planning programme in the Philippines. Journal of Biosocial Science 44(1): 27-41.

18. RamaRao, S., M. Lacuesta, M. Costello, et al. 2003. The Link Between Quality of Care and Contraceptive Use. International Family Planning Perspectives 29(2).

19. Hong, R., L. Montana, V. Mishra. 2006. Family Planning Services Quality as a Determinant of Use of IUD in Egypt. BMC Health Services Research 6: 79. 
20. Koenig, M.A. 2003. The Impact of Quality of Care on Contraceptive Use: Evidence from Longitudinal Data from Rural Bangladesh. Baltimore: Johns Hopkins University.

21. Arends-Kuenning M., F.L. Kessy. 2007. The impact of Demand Factors, Quality of Care and Access to Facilities on Contraceptive Use in Tanzania. Journal of Biosocial Science 39: 1-26.

22. Sanogo D., S. RamaRao, H. Johnes, P. N'diaye, B. M'bow, C.B. Diop. 2003. Improving Quality of Care and Use of Contraceptives in Senegal. African Journal of Reproductive Health 7: 57-73.

23. Martin, M. and J. Ovretveit. 2001. Can We Save Money by Improving Quality? BMJ Quality and Safety 20: 293-296.

24. Bodenheimer, T., E. Wagner, K. Grumbach. 2002. Care for Patients with Chronic Illness. JAMA 288: 1909-1914.

25. WHO and Johns Hopkins Bloomberg School of Public Health Center for Communication Programs. 2011. Family Planning: A Global Handbook for Providers, 2011 Update.

26. WHO. 2006. Quality of Care: A Process for Making Strategic Choices in Health Systems.

27. Massoud, R., K. Askov, J. Reinke, L. M. Franco, T. Bornstein, E. Knebel, C. MacAulay. 2001. A Modern Paradigm for Improving Healthcare Quality. QA Monograph Series 1(1) Bethesda, MD: Published for the U.S. Agency for International Development (USAID) by the Quality Assurance Project.

28. Steyn, P. 2014. WHO-supported UPTAKE Project presentation. Summary Report of the Measuring and Monitoring Quality of Care Meeting Sponsored by the Packard Foundation. Washington, DC.

29. Horstman, R. et al. 2002. Monitoring and Evaluation of Sexual and Reproductive Health Interventions: A Manual for the EC/UNFPA Initiative for Reproductive Health in Asia. Netherlands Interdisciplinary Demographic Institute and London School of Hygiene and Tropical Medicine.

30. Creel, L., J. Sass, N. Yinger. 2002. Overview of Quality of Care in Reproductive Health: Definitions and Measurements of Quality. New Perspectives on Quality of Care 1. Population Council and Population Reference Bureau.

31. USAID POP Briefs. 2001. Ensuring Quality Family Planning Services throughout the World.

32. WHO. 2007. Everybody's Business. Strengthening Health Systems to Improve Health Outcomes. WHO's Framework for Action.

33. www.who.int/healthsystems/hss_glossary/en/index8.html

34. Miller, K., R. Miller, I. Askew, et al. 1998. Clinic-based Family Planning and Reproductive Health Services in Africa: Findings from Situation Analysis Studies. Population Council.

35. EngenderHealth. 2011. The SEED Assessment Guide for Family Planning Programming. New York.

36. EngenderHealth. The ACQUIRE Project. The Fundamentals of Care: Ensuring Quality in Facility-Based Services: A Resource Package.

37. Marie Stopes International. Assessing Client Profile and Evaluating Client Satisfaction Through Exit Interviews: Guidelines. London.

38. Weinberger, M. 2014. Overview of MSl's Work. Presentation at Measuring and Monitoring Quality of Care Meeting.

39. United Nations. 1995. Declaration and Platform for Action. Fourth World Conference on Women, Beijing.

40. International Planned Parenthood Federation. 1994. Charter on Sexual and Reproductive Rights. London.

41. Erdman, J.N. and R.J. Cook. 2008. Reproductive Rights. International Encyclopedia of Public Health. Kirs, ed. Oxford: Academic Press. 532-538. 
42. CARE. 2001. Incorporation of a Rights-Based Approach into CARE's Program Cycle: A Discussion Paper for CARE's Program Staff.

43. WHO and Office of UN High Commissioner of Human Rights. A Human Rights-based Approach to Health.

44. UNFPA and WHO. 2015. Ensuring Human Rights Within Contraceptive Service Delivery: Implementation Guide.

45. Family Planning 2020. 2014. Rights and Empowerment Principles for Family Planning.

46. Kumar, J., L. Bakamjian, S. Harris, M. Rodriguez, N. Yinger, C. Shannon, K. Hardee. 2014. Voluntary Family Planning Programs that Respect, Protect and Fulfill Human Rights: Conceptual Framework Users' Guide. Washington, DC: Futures Group.

47. Hardee, K. 2014. Human Rights and Quality of Care. Presentation at Measuring and Monitoring Quality of Care Meeting. Washington, DC.

48. Kumar, J. 2014. Uganda Prioritizes Voluntary Family Planning and Charts Course for a Rights-based Approach. Champions4Choice blog post. EngenderHealth.

49. Rodriguez, M., S. Harris, K. Willson, K. Hardee. 2013. Voluntary Family Planning Programs that Respect, Protect and Fulfill Human Rights: A Systematic Review of the Evidence. Washington, DC: Futures Group.

50. Bustreo, H. 2013. Women's and Children's Health: Evidence of Impact of Human Rights. WHO.

51. RESPOND Project. 2013. A Fine Balance: Contraceptive Choice in the 21 ${ }^{\text {st }}$ Century-An Action Agenda. Report of the September 2012 Bellagio conference. New York: EngenderHealth RESPOND Project.

52. Population Council. 2015. Summary Report of the Measuring and Monitoring Quality of Care Meeting. Unpublished. 
THE David

Lucile Packard

Foundation
One Dag Hammarskjold Plaza

ONew York, New York 10017

popcouncil.org 